\title{
Effect of Heat Treatment on Some Mechanical Properties of 7075 Aluminium Alloy
}

\author{
Adeyemi Dayo Isadare ${ }^{\mathrm{a}}$, Bolaji Aremo ${ }^{\mathrm{b}}$, Mosobalaje Oyebamiji Adeoye ${ }^{\mathrm{c}}$, \\ Oluyemi John Olawale ${ }^{\mathrm{c} *}$, Moshood Dehinde Shittu ${ }^{\mathrm{c}}$ \\ a Prototype Engineering Development Institute Ilesa, Nigeria \\ ${ }^{\mathrm{b}}$ Centre for Energy Research and Development, Obafemi Awolowo University, Ile-Ife, Nigeria \\ ${ }^{\mathrm{c}}$ Department of Materials Science and Engineering, Obafemi Awolowo University, Ile-Ife, Nigeria
}

Received: April 14, 2012; Revised: September 3, 2012

\begin{abstract}
This paper reports the effects of annealing and age hardening heat treatments on the microstructural morphology and mechanical properties of $7075 \mathrm{Al}$ alloy. The material was cast in the form of round cylindrical rods inside green sand mould from where some samples were rapidly cooled by early knockout and others gradually cooled to room temperature. From the samples that were gradually cooled some were annealed while others were age hardened. Both the as-cast in each category and heat treated samples were subjected to some mechanical tests and the morphology of the resulting microstructures were characterised by optical microscopy. From the results obtained there is formation of microsegregations of $\mathrm{MgZn}_{2}$ during gradual solidification which was not present during rapid cooling. It was also found out that age hardening and annealing heat treatment operation eliminated these microsegregations and improve mechanical properties of $7075 \mathrm{Al}$ alloy. It is concluded that microsegregation can be eliminated by rapid solidification and appropriate heat treatment process.
\end{abstract}

Keywords: 7075 aluminium, microsegregation, precipitation hardening, annealing, magnesium alloy, strength

\section{Introduction}

Aluminium and its alloys are used in a variety of cast and wrought forms and conditions of heat treatment. For over 70 years, it ranks next to iron and steel in the metal market. The demand for aluminium grows rapidly because of its unique combination of properties which makes it becomes one of the most versatile of engineering and construction material $^{1-3}$.

The optimum properties of aluminium are achieved by alloying additions and heat treatments. This promotes the formation of small hard precipitates which interfere with the motion of dislocations and improve its mechanical properties $^{4-7}$. One of the most commonly used aluminium alloy for structural applications is $7075 \mathrm{Al}$ alloy due to its attractive comprehensive properties such as low density, high strength, ductility, toughness and resistance to fatigue ${ }^{8-11}$. It has been extensively utilized in aircraft structural parts and other highly stressed structural applications ${ }^{12-16}$.

But aluminium-zinc alloy as it is in $7075 \mathrm{Al}$ alloy is susceptible to embrittlement because of microsegregation of $\mathrm{MgZn}_{2}$ precipitates which may lead to catastrophic failure of components produced from $\mathrm{it}^{17,18}$. The alloy is also susceptibility to stress corrosion cracking ${ }^{19,20}$. This is due to inhomogeneity of the alloy and inherent residual stresses associated with its fabrication methods.

The formation of these microsegregations (hard precipitates) and inherent residual stresses that are associated

*e-mail: jooolawale@yahoo.com with their fabrication methods have serious negative effect on their mechanical properties ${ }^{18}$. Hence, this study is aimed at resolving the problems of microsegregations and inherent residual stresses that are associated with aluminium-zinc for improved service performance. The objectives of the work are to investigate the effects of annealing and precipitation hardening (age hardening) heat treatment on the microstructure, hardness, tensile strength, and impact strength of aluminium-zinc alloy.

\section{Experimental Procedure}

\subsection{Material preparation}

The present investigation was carried out on $7075 \mathrm{Al}$ alloy composition shown in Table 1 . The material was cast in the form of round cylindrical rods of $20 \mathrm{~mm}$ diameter and $500 \mathrm{~mm}$ long. Some of the cast rods were rapidly cooled to room temperature by knocking them out 5 minutes after castings while the others were cooled gradually inside the mould to room temperature. Round tensile samples and impact test samples were machined from these categories of rods according to British Standard BSEN 10002-1:1990 and ASTM Standard E 602-91 respectively ${ }^{21,22}$. The tensile test samples have a gauge length of $30 \mathrm{~mm}$ and diameter of $5 \mathrm{~mm}$. The impact test samples were $\mathrm{V}$ notched to a depth of $2 \mathrm{~mm}$. Samples were also sectioned from cast rods for metallographic and hardness tests. 


\subsection{Heat treatment}

Two types of heat treatments were carried out namely annealing and precipitation hardening on sample machined from castings that were gradually cooled. Annealing was carried out by heating the already machined, metallographic and hardness test piece samples to $470{ }^{\circ} \mathrm{C}$, soaking them at this temperature for 3 hours and then furnace cooled. Precipitation hardening was carried out by first solution treated another set of machined, metallographic and hardness test piece samples at a temperature of $465^{\circ} \mathrm{C}$ for 2 hours followed by rapid quenching in cold water. These quenched samples were then subjected to a precipitation hardening treatment (age hardening) by heating them to $120{ }^{\circ} \mathrm{C}$, holding them at this temperature for 5 hours and then followed by air cooling to room temperature.

\subsection{Tensile testing}

Tensile testing of all these specimens was conducted per British Standard BSEN 10002-1:1990. Three samples were tested from each heat-treated condition and as cast samples. The tests were carried out at room temperature with a crosshead speed of $1 \mathrm{~mm} / \mathrm{min}$ using a computerised Instron 3369 electromechanical testing machine. Load - displacement plots were obtained on an X-Y recorder and ultimate tensile strength and percentage elongation values were calculated from this load - displacement diagrams. The average values from three test samples are reported here.

\subsection{Impact testing}

Impact testing of all these specimens was conducted per ASTM Standard E 602-91. Three samples were tested from each heat-treated condition and as cast samples. The tests were carried out using Izod impact test method on Houndsfield balance impact-testing machine. The amount of impact energy absorbed by the specimen before yielding was read off on the calibrated scale attached to the machine as a measure of impact strength in Joules. The average values from three test samples are reported here.

\subsection{Hardness test}

The control and the heat treated samples were subjected to the Brinell hardness test using the Houndsfield extensometer in compression mode. The specimens were polished to 600 microns and mounted on the machine using a dwell time of 15 seconds. The diameter of the impression left by the ball was then measured using the Brinell calibrated hand lens and the corresponding Brinell hardness number was determined.

Table 1. Chemical composition of 7075 aluminium alloy.

\begin{tabular}{cc}
\hline Element & \%wt. \\
\hline $\mathrm{Zn}$ & 5.6 \\
$\mathrm{Mg}$ & 2.5 \\
$\mathrm{Cu}$ & 1.6 \\
$\mathrm{Al}$ & Balance \\
\hline
\end{tabular}

\subsection{Optical metallography}

The heat treated and as cast samples were taken through the process of metallography: sample selection, mounting, grinding, polishing and etching. The morphology of the microstructures were then characterised by optical microscopy after etching with sodium hydroxide.

\section{Results and Discussions}

Figures 1 to 4 show the microstructures of the specimen in as-cast (gradually cooled), as-cast (rapidly cooled), annealed and aged hardening condition respectively. The microstructure of as-cast (gradually cooled) sample (Figure 1) shows microsegeregation of $\mathrm{MgZn}_{2}$ in aluminium matrix while as-cast (rapidly cooled) sample (Figure 2) shows fine grains of $\mathrm{MgZn}_{2}$ phase which is uniformly distributed in the aluminium matrix. The microstructure of annealed sample (Figure 3) shows coarse grains of $\mathrm{MgZn}_{2}$ phase which is non-uniformly distributed in the aluminium matrix while the microstructure of age hardening sample (Figure 4) shows the finely dispersed precipitate of $\mathrm{MgZn}_{2}$ in aluminium matrix. The presence of dispersed precipitate of $\mathrm{MgZn}_{2}$ correspond with the result of Salamci ${ }^{23}$ and Du et al. ${ }^{24}$ who discovered that aging heat treatment of Al- $\mathrm{Zn}-\mathrm{Mg}-\mathrm{Cu}$ alloys lead to the formation of $\mathrm{MgZn}_{2}$ intermetallic phase in the structure.

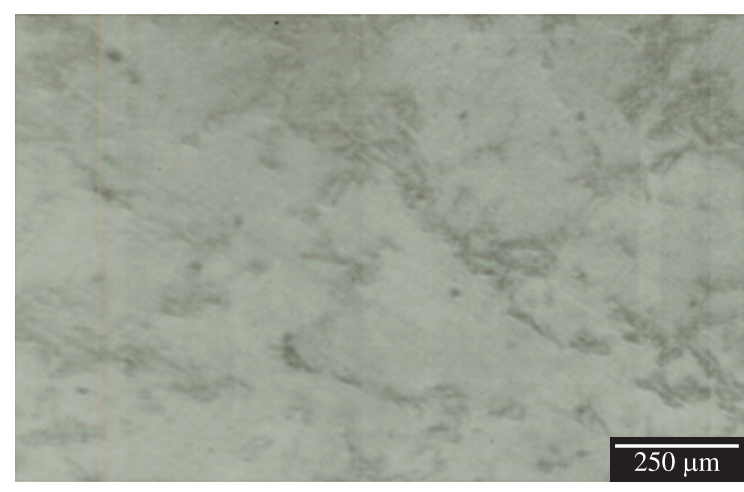

Figure 1. Microstructure of gradually cooled as-cast $7075 \mathrm{Al}$ alloy showing microsegregation of $\mathrm{MgZn} 2$ in $\mathrm{Al}$ matrix.

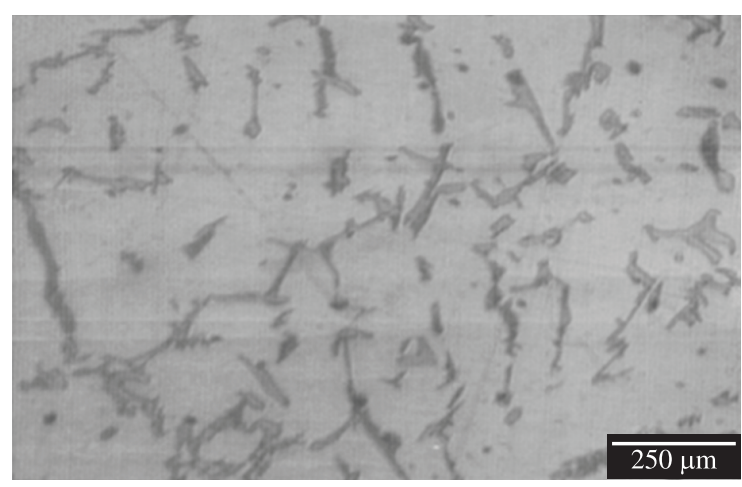

Figure 2. Microstructure of rapidly cooled as-cast $7075 \mathrm{Al}$ alloy showing MgZn2 Phase in Al matrix. 
In their study on evolution of eutectic structures in $\mathrm{Al}-\mathrm{Zn}-\mathrm{Mg}-\mathrm{Cu}$ alloys Fan et al. ${ }^{25}$, reported that several coarse intermetallic phases such as $\mathrm{MgZn}_{2}, \mathrm{Al}_{2} \mathrm{Mg}_{3} \mathrm{Zn}_{3}, \mathrm{Al}_{2} \mathrm{CuMg}$, $\mathrm{Al}_{2} \mathrm{Cu}, \mathrm{A}_{17} \mathrm{Cu}_{2} \mathrm{Fe}, \mathrm{Al}_{13} \mathrm{Fe}_{4}$ and $\mathrm{Mg}_{2} \mathrm{Si}$ can be formed below the solidus line during solidification of as-cast 7000 series of aluminium alloys as a result of solute redistribution of metals. This report supports our finding of microsegeregation of $\mathrm{MgZn}_{2}$ in $7075 \mathrm{Al}$ alloy in gradually cooled sample. In a rapidly cooled sample there was no room for solute redistribution of $\mathrm{Mg}$ and $\mathrm{Zn}$ and hence microsegregation of $\mathrm{MgZn}_{2}$ is not formed. However, during the soaking period of heat treatment operations the microsegregations formed after gradual cooling are dissolved to form a homogeneous phase and they disappeared after subsequent cooling. The elimination of microsegregations after annealing and aging heat treatment operations in the present investigation is in agreement with the findings of Guo et al. ${ }^{26}$ who finds out that solution treatment markedly reduce the degree of microseregation in 2024 wrought aluminium alloy.

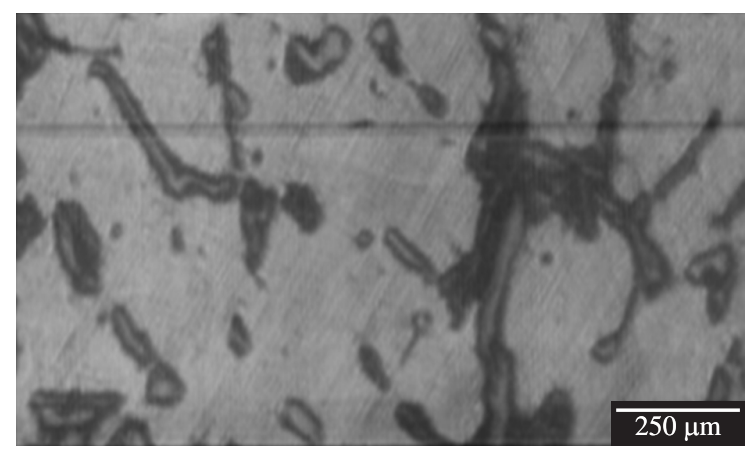

Figure 3. Microstructure of annealed $7075 \mathrm{Al}$ alloy showing $\mathrm{MgZn} 2$ phase in Al matrix.

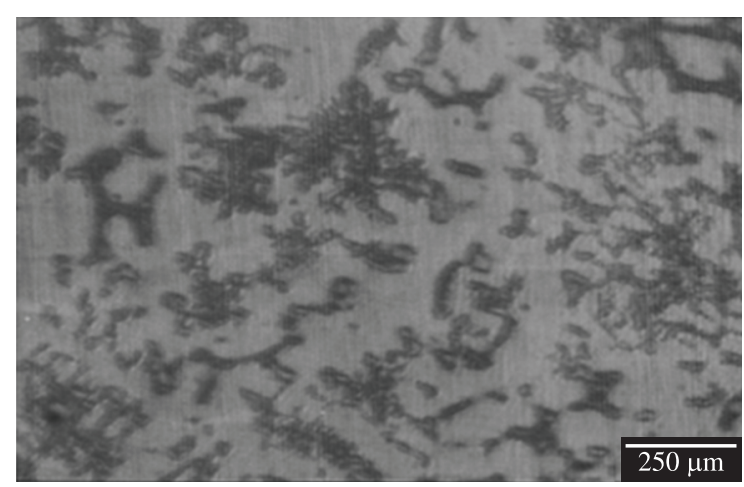

Figure 4. Microstructure of aged hardening $7075 \mathrm{Al}$ alloy showing precipitate of $\mathrm{MgZn} 2$ in $\mathrm{Al}$ matrix.
From the results of mechanical test as presented in Table 2; the as-cast (gradually cooled) samples has the highest ultimate tensile and yield strengths followed by age hardened samples, as-cast (rapidly cooled) and annealed samples. The as-cast (gradually cooled) sample has the highest hardness and strength because of the presence of miccrosegregations in its structure which embrittles $7075 \mathrm{Al}$ alloy. The reason for the observed trend in hardness and strength in the remaining samples is due to the variations in their grain size. This is in agreement with the findings of Kenji et al. ${ }^{27}$ which indicated that solid-solution and grain refinement contribute to the hardening of Al-Mg alloys. Also, it is well reported in previous studies that fine-grained materials has more grain boundaries; and are harder and stronger than coarse grained materials that has less grain boundaries ${ }^{28-30}$. Since age hardened sample has more grain boundaries than as-cast (rapidly cooled) and annealed samples there is more impediment to dislocation motion during deformation and hence it is harder and stronger ${ }^{31}$. For most materials the yield strength $\sigma_{y}$ varies with grain size according to Hall-Petch relation:

$\sigma_{\mathrm{y}}=\sigma_{\mathrm{o}}+\mathrm{k}_{\mathrm{y}} \mathrm{d}^{-1 / 2}$

In this expression $d$ is the average grain diameter, $\sigma_{\mathrm{y}}$ and $\mathrm{k}_{\mathrm{y}}$ and are constants for a particular material.

The improvement in yield strength and ultimate tensile strength as a result of grain size can also be explained from the microstructures perspectives. The finer these grains are the more the boundaries. During plastic deformation, slip or dislocation movement must take place across these grain boundaries. Since polycrystalline grains are of different crystallographic orientations at the grain boundaries, a dislocation passing from one grain to another will have to change its direction of motion. Such changes of direction causes impediment to dislocation movement, and increases both the yield strength and ultimate tensile strength. Because age hardening samples have the highest number of grain boundaries, dislocation movement becomes more and more difficult during plastic deformation. This is responsible for highest yield strength and ultimate tensile strength observed in age hardening samples. Also, $7075 \mathrm{Al}$ alloy used for this study contains about $5.6 \%$ zinc $(\mathrm{Zn})$ and $2.5 \%$ magnesium $(\mathrm{Mg})$. These two alloying elements lead to increase in the strength of this alloy through formation of $\mathrm{MgZn}_{2}$ precipitate within the structure as the result of aging heat treatment. This result corresponds with Du et al. ${ }^{24}, \mathrm{Li}$ and Peng ${ }^{11}$, Demir and Gündüz ${ }^{32}$ and Kaya et al. ${ }^{33}$ who concluded that $\mathrm{Al}-\mathrm{Zn}-\mathrm{Mg}$ alloy can get the highest strength level in natural and artificial ageing.

Table 2. Results of mechanical testing for as-cast and heat treated Al-Zn-Mg samples.

\begin{tabular}{cccccc}
\hline Samples & $\begin{array}{c}\text { Yield strength } \\
\text { (MPa) }\end{array}$ & $\begin{array}{c}\text { Ultimate tensile } \\
\text { strength (MPa) }\end{array}$ & $\begin{array}{c}\text { Percentage } \\
\text { elongation }\end{array}$ & $\begin{array}{c}\text { Hardness number } \\
(\mathbf{H B})\end{array}$ & $\begin{array}{c}\text { Impact strength } \\
(\mathbf{J})\end{array}$ \\
\hline As-cast (gradually cooled) & 526 & 603 & 10 & 201 & 9.2 \\
As-cast (rapidly cooled) & 467 & 529 & 17 & 157 & 17.7 \\
Annealing & 297 & 414 & 21 & 124 & 22.4 \\
Age hardening & 501 & 575 & 15 & 171 & 14.7 \\
\hline
\end{tabular}


Annealing sample has the highest percentage elongation followed by as-cast (rapidly cooled), age hardening samples, and as-cast (gradually cooled). This is partly due to increase in grain coarsening which leads to an increase in the grain boundary area which increases the amount of energy required for the movement of dislocations required to cause fracture ${ }^{34-36}$. Thus, the material can withstand a higher plastic deformation before the final fracture. However, the percentage elongation of as-cast (gradually cooled) is very small because of embrittlement of $7075 \mathrm{Al}$ alloy as a result of microsegregation of $\mathrm{MgZn}_{2}$.

As-cast (gradually cooled) sample has extremely high hardness as a result of its brittle structure. From the remaining three samples age hardening heat treatment samples has the highest hardness followed by as-cast (rapidly cooled) and annealed samples. The highest hardness values developed by age hardening samples can be attributed to precipitation of coherent and finely dispersed $\mathrm{MgZn}_{2}$ phases which serves as foreign atom or inclusion in the lattice of the host crystal in the solid solution; this causes more lattice distortions which makes the alloy harder. In the previous study solid solution strengthening from elastic distortions is produced by substitutional atoms of $\mathrm{Mg}$ and $\mathrm{Zn}$ in aluminium matrix ${ }^{37}$. Hence, the main strengthening mechanism in these alloys is precipitation hardening by structural precipitates of $\mathrm{MgZn}_{2}$ formed during artificial ageing. The precipitate particles act as obstacles to dislocation movement and thereby strengthen the heat-treated alloys.

The impact strength followed the same trends as percentage elongation with annealing sample been the highest and as-cast (gradually cooled) sample been the least. This is because impact strength is also a measure of material's ductility, and ductility is inversely related to strength ${ }^{38}$.

\section{References}

1. American Society for Metals - ASM. Handbook. Properties and selection. Nonferrous Alloys and Special-Purpose Materials ASM International Handbook Committee; 1990 vol. 2, p. 137-38.

2. Machler R, Uggowitzer PJ, Solenthaler C, Pedrazzoli RM and Spiedel MO. Structure, mechanical properties, and stress corrosion behaviour of high strength spray deposited 7000 series aluminium alloy. Materials Science Technology. 1991; 7:447-51. http://dx.doi.org/10.1179/026708391790183880

3. Chee FT and Mohamad RS. Effect of hardness test on precipitation hardening aluminium alloy 6061-T6. Chiang Mai Journal of Science. 2009; 36(3):276-86.

4. Smallman RE. Modern physical metallurgy. 4th ed. London: Butterworths \& Co.; 1985.

5. Lavernia EJ, Rai G and Grant NJ. Rapid solidification processing of 7xxx aluminium alloys: a review. Materials Science and Engineering. 1990; 79:211-21. http://dx.doi. org/10.1016/0025-5416(86)90406-4

6. Sanctis MD. Structure and properties of rapidly solidified ultrahigh strength $\mathrm{Al}-\mathrm{Zn}-\mathrm{Mg}-\mathrm{Cu}$ alloys produced by spray deposition. Materials Science and Engineering. 1991; A141:103-21.

7. White J, Mingard K, Hughes IR and Palmer IG. Aluminium alloys with unique property combinations by spray casting. Powder Metallurgy. 1994; 37(2):129-32.

\section{Conclusions}

From the outcome of this study, there is formation of microsegregations of $\mathrm{MgZn}_{2}$ during the gradual solidification of 7075 aluminium alloy due to solute redistribution of $\mathrm{Mg}$ and $\mathrm{Zn}$ but this was suppressed during rapid solidification. However, the microsegregations that were formed when it was gradually cooled are dissolved to form a homogeneous phase during the soaking period of heat treatment operations. As a result of age hardening heat treatment operation there is formation of small and finely uniform dispersed precipitate of $\mathrm{MgZn}_{2}$ in the aluminium matrix while coarse grains of $\mathrm{MgZn}_{2}$ phase was formed in aluminium matrix as a result of annealing heat treatment operation.

It has been found that rapid solidification process and heat treatment eliminate the formation of microsegregation, and significantly improved some mechanical properties. Age hardening heat treatment operation was found to improve yield strength, ultimate tensile strength and hardness values but lower ductility and impact strength. On the other hand annealing heat treatment operation improves impact strength and ductility but lower yield strength, ultimate tensile strength and hardness values. Therefore, annealing treatment of the alloy will be suitable for applications involving high toughness and ductility while age hardening treatment will be suitable for applications that require high ultimate tensile strength, yield strength and hardness values.

Finally, it is concluded that the formation of microsegregation embrittle 7075 aluminium alloy, and subsequently have negative effects on its mechanical properties and its application. This can be addressed by rapid solidification and appropriate heat treatment process.

8. Heinz A and Haszler A. Recent development in aluminum alloys for aerospace applications. Materials Science and Engineering A. 2000; 280(1):102-7. http://dx.doi.org/10.1016/ S0921-5093(99)00674-7

9. Williams JC and Starke Junior EA. Progress in structural materials for aerospace systems. Acta Materialia. 2003; 51(19):5775-99. http://dx.doi.org/10.1016/j.actamat.2003.08.023

10. Clark R, Coughran B, Traina I, Hernandez A, Scheck T, Etuk $\mathrm{C}$ et al. On the correlation of mechanical and physical properties of 7075-T6 Al alloy. Engineering Failure Analysis. 2005; 12:520-6. http://dx.doi.org/10.1016/j. engfailanal.2004.09.005

11. Li JF and Peng ZW. Mechanical properties, corrosion behaviors and microstructures of 7075 aluminium alloy with various aging treatments. Transactions of Nonferrous Metal Society of China. 2008; 18(4):755-62. http://dx.doi.org/10.1016/ S1003-6326(08)60130-2

12. Woei-Shyan LS and Wu-Chung S. The strain rate and temperature dependence of the dynamic impact properties of 7075 aluminum alloy. Journal of Materials Process and Technology. 2000; 100:116-22. http://dx.doi.org/10.1016/ S0924-0136(99)00465-3

13. Lin G, Zhang H, Zhang X, Han D, Zhang Y and Peng D. Influences of processing routine on mechanical properties and structures of 7075 aluminium alloy thick plate. Transactions of Nonferrous Metal Society of China. 2003; 13(4):809-13. 
14. Shwe WHA, Kay TL and Waing KKO. The effect of ageing treatment of aluminum alloys for fuselage structure-light aircraft. World Academy of Science, Engineering and Technology. 2008; 46:696-9.

15. Zhao T and Jiang Y. Fatigue of 7075-T651 aluminum alloy. International Journal of Fatigue. 2008; 830:834-849. http:// dx.doi.org/10.1016/j.ijfatigue.2007.07.005

16. Mohammad T and Esmaeil E. Mechanical and anisotropic behaviors of 7075 aluminum alloy sheets. Materials and Design. 2010, 32(2):1594-9. http://dx.doi.org/10.1016/j. matdes.2010.09.001

17. John VB. Introduction to engineering materials. London: Macmillan Press Limited; 1992.

18. Meng-Shan T, Pei-Ling S, Po-We K and Chih-Pu C. Influence of severe plastic deformation on precipitation hardening in an Al-Mg-Si alloy: microstructure and mechanical properties. Materials Transactions. 2009; 50(4):771-5. http://dx.doi. org/10.2320/matertrans.MRA2008468

19. Ramesh SK, Kondaiah G, Venkatachalam P and Ravisankar B. Stress corrosion cracking of Al 7075 alloy processed by equal channel angular pressing. International Journal of Engineering, Science and Technology. 2010; 2(12):53-61.

20. Silva G, Rivolta B, Gerosa R and Derudi U. Study of the SCC behavior of 7075 aluminum alloy after one-step aging at $163^{\circ} \mathrm{C}$. Journal of Materials Engineering and Performance. 2012. http://dx.doi.org/10.1007/s11665-012-0221-4

21. British Standard - BSEN. 10002-1: Tensile testing of metallic materials. London: Macmillan; 1990. part 1.

22. American Society for Testing and Materials - ASTM. Standard E 602-91: Standard test method for sharp-notch impact testing with flat specimens. Philadelphia: American Society for Testing and Materials; 1992.

23. Salamci E. Ageing behaviour of spray cast $\mathrm{Al}-\mathrm{Zn}-\mathrm{Mg}-\mathrm{Cu}$ alloys. Turk Journal of Engineering and Environmental Science. 2001; 25(6):681-686.

24. Du ZW, Sun ZM, Shao BL, Zhou TT and Chen CQ. Quantitative evaluation of precipitates in an $\mathrm{Al}-\mathrm{Zn}-\mathrm{Mg}-\mathrm{Cu}$ alloy after isotermal aging. Materials Characerization. 2006; 56:121-8. http://dx.doi.org/10.1016/j.matchar.2005.10.004

25. Fan X, Jiang D, Meng Q, Zhang B and Wang T. Evolution of eutectic structures in $\mathrm{Al}-\mathrm{Zn}-\mathrm{Mg}-\mathrm{Cu}$ alloys during heat treatment. Transactions of Nonferrous Metal Society of China. 2006; 16:577-81. http://dx.doi.org/10.1016/ S1003-6326(06)60101-5

26. Guo H, Yang $X$ and Zang M. Microstructure characteristics and mechanical properties of reoformed wrought aluminium alloy 2024. Transactions of Nonferrous Metal Society of China. 2008; 18:555-61. http://dx.doi.org/10.1016/ S1003-6326(08)60097-7
27. Kenji K, Tetsuro H, Tomoharu T and Zenji Horita. Fabrication and characterization of supersaturated $\mathrm{Al}-\mathrm{Mg}$ alloys by severe plastic deformation and their mechanical properties. Materials Transactions. 2009; 50(1):76 to 81.

28. Alexandre G, Tsutomu I, Xiaoyong Y, Yoshinobu M and Goroh I. Friction stir welding of a commercial 7075-T6 aluminium alloy: grain refinement, thermal stability and tensile properties. Materials Transactions. 2004; 45(8):2503-8. http://dx.doi. org/10.2320/matertrans. 45.2503

29. Roberto BF and Terence GL. Using severe plastic deformation for the processing of advanced engineering materials. Materials Transactions. 2009; 50(7):1613-9. http://dx.doi.org/10.2320/ matertrans.MF200913

30. Chen XH, Lu L and Lu K. Grain size dependence of tensile properties in ultrafine-grained $\mathrm{Cu}$ with nanoscale twins. Scripta Materialia. 2011; 64:311-4. http://dx.doi.org/10.1016/j. scriptamat.2010.10.015

31. Callister WD. Materials science and engineering: an introduction. 4th ed. New York: John Willey and Son Inc.; 1997.

32. Demir H and Gündüz S. The effect of aging on machinability of 6061 aluminium alloy. Material and Design. 2009; 30:1480-3. http://dx.doi.org/10.1016/j.matdes.2008.08.007

33. Kaya H, Uçar M, Cengiz A, Özyürek D, Çalişkan A and Ergün RE. The effect of aging on the machinability of AA7075 aluminium alloy. Scientific Research and Essays. 2012; 7(27):2424-30.

34. Liao X Z, Zhao Y H and Zhu YT. Grain-size effect on the deformation mechanisms of nanostructured copper processed by high-pressure torsion. Journal of Applied Physics. 2004; 96(1):636-40. http://dx.doi. org/10.1063/1.1757035

35. Zheng HW, Zhan YG, Chen Z, Lu C and Mai YW. Roles of grain boundary and dislocations at different deformation stages of nanocrystalline copper under tension. Physics Letters A. 2009; 373:570-4. http://dx.doi.org/10.1016/j. physleta.2008.12.019

36. Kumar R., Nicola L and Van der Giessen E. Density of grain boundaries and plasticity size effects: A discrete dislocation dynamics study. Materials Science and Engineering A. 2009; 527:7-15. http://dx.doi.org/10.1016/j. msea.2009.08.072

37. Zhao YH, Liao XZ, Jin Z, Valiev RZ and Zhu YT. Microstructures and mechanical properties of ultrafine grained $7075 \mathrm{Al}$ alloy processed by ECAP and their evolutions during annealing. Acta Materialia. 2004; 52:4589-99. http://dx.doi.org/10.1016/j. actamat.2004.06.017

38. Rajan TV, Sharma CP and Sharma A. Principles and techniques of heat treatment. New Delhi: Prentice-Hall of India Private Limited; 1988. 